\title{
Application of the Chow method for evaluation of morphometric parameters of the sunflower root system
}

\author{
Igor Vorotnikov, Sergey Bogatyrev*, and Aleksandr Rozanov \\ Saratov State Agrarian University named after N.I. Vavilov, 410012, 1, Teatralnaya sq., Saratov, \\ Russian Federation
}

\begin{abstract}
When growing sunflower, great importance is provided to the issue of accumulation and preservation of moisture in deep soil horizons, which in turn affects the productivity of crops. In arid regions, providing plants with moisture is of particular importance. The technologies of conservation agriculture in relation to sunflower cultivation allow varying the depth of autumn tillage from 17 to $33 \mathrm{~cm}$, which, in combination with the metered use of mineral fertilizers and considering the difference in moisture consumption for the growing season from a meter layer of soil, provide an increase in yield compared to the traditional main autumn tillage. Moreover, the ratio of income from the sale of sunflower seeds grown in an arid steppe to production costs depends on the combination of the depth of strip processing and the dose of fertilization. Wherein, in the main zones of commercial sunflower production, high yield increases are provided by the application of nitrogen-phosphorus fertilizers, which contribute to the intensive formation of underground vegetative organs, which has unlimited growth in length and positive geotropism. The article presents the results of the application of multivariate regression analysis to study the morphobiological features of formation of the root system of sunflower grown using Strip-Till technology on the experimental field of the Povolzhye Educational and Scientific Production Association of the Saratov State Agrarian University named after N.I. Vavilov. The results of the morphometric assessment indicate a better development of the root system of plants in the treated strips compared to traditional types of basic tillage. To determine the limits of applicability of the piecewise linear regression model and develop practical recommendations for implementation of resource-saving potential of the Strip-Till technology in the dry steppe zone of the South-East of Russia used a reliable and sensitive criterion based on the method of J. Chow.
\end{abstract}

\section{Introduction}

The digital transformation of the Russian agroeconomy presupposes the accelerated introduction of advanced farming technologies [1]. In the conditions of arid agriculture in

\footnotetext{
* Corresponding author: tettet@inbox.ru
} 
the Saratov region, the Strip-Till technology of strip tillage, an alternative to its traditional types, seems to be promising.

The purpose of this article is to find a rational combination of morphometric and agrophysical factors of the root system of a highly profitable row crop - sunflower, during the cultivation of which the maximum possible resource-saving potential of the Strip-Till technology is implemented.

Sowing annual sunflower (Helianthus annuus) is a herb that, according to botanical classification, belongs to the genus Sunflower from the Asteraceae or Compositae families. The root system is tap-root one, which can penetrate to a depth of $3 \mathrm{~m}$ or more. The length of the root system is much higher than the height of the aboveground part of plants (according to some sources, $3 \ldots 10$ times). The roots of sunflower plants grow quite quickly and already at the stage of $4 \ldots .5$ leaves in plants, their root length reaches $60 \ldots 100 \mathrm{~cm}$. Most of the roots are located at a depth of $0 \ldots 50 \mathrm{~cm}$. The most intensive development of the root system occurs during the period of plant growth, and the bulk of the roots is formed during the period from formation of the basket to the moment of flowering.

Due to presence of a well-developed and deeply penetrating main root, the sunflower can withstand drought and absorb nutrients and soil moisture well. However, this is in the event that the soil is not compacted and nothing interferes with the growth of the root (for example, a dense plow sole can be an obstacle). In wet conditions, sunflower roots develop closer to the soil surface, and in dry climates they penetrate deeper. In the event that sunflower plants, due to the presence of a plow sole, form a superficial root system, then they will be less resistant to wind and will lie down.

The sunflower root system has a powerful main stem, which under normal conditions penetrates to a depth of $4 \mathrm{~m}$ (on average $150 \ldots 180 \mathrm{~cm}$ ) and extends to the sides up to $100 \ldots 160 \mathrm{~cm}$ (on average $60 \mathrm{~cm}$ ). The depth of root penetration is $5 \ldots 10$ times the height of the plant. In the phase of cotyledons with a runner height of $3 \ldots 4 \mathrm{~cm}$, the root length reaches $10 \mathrm{~cm}$, and in the phase of $8 \ldots 10$ true leaves, the root system penetrates into the soil to a depth of $1 \mathrm{~m}$. In dry conditions, the roots penetrate deeper. In presence of groundwater, the roots are able to penetrate to a depth of $5 \ldots 8 \mathrm{~m}$ and use this water for the growth and development of plants.

In addition to the main object of field experiments - sunflower - similar measures were carried out for sowing corn or maize (Zéa máys) - an annual herbaceous cultivated plant. The root system is powerful, fibrous, multi-tiered, highly branched; on soils with a loose subsoil, it can penetrate to a depth of $3 \mathrm{~m}$. The radius of horizontal propagation is more than $1 \mathrm{~m}$. Most of the roots are located at a depth of $0 \ldots 40 \mathrm{~cm}$.

The corn seed sprouts with one germinal root. The nodal roots of the first tier are formed on the underground nodes of the stem when 3...4 leaves appear, the second tier - in the phase of 5...6 leaves. In the phase of sweeping, aerial (supporting) roots are formed from the stem nodes located closer to the soil surface, which prevent the plants from lodging, and with sufficient moisture and hilling, they take root. The maximum development of the root system occurs during the wax ripeness phase. Its development is facilitated by a moisture content of $70 \ldots 80 \%$ of the lowest moisture capacity and an optimal soil density equal to $1.1 \ldots 1.3 \mathrm{~g} / \mathrm{cm} 3$, the provision of available nutrients, primarily phosphorus, in the initial period. Under conditions of soil drought, root growth is suppressed, their branching decreases, and the appearance of successive layers of nodal roots is delayed.

The root system of maize has two groups of roots: embryonic and adventitious. The first one includes the main and lateral embryonic roots. The second group is made up of nodal roots - aboveground and underground (aerial). The first layer of roots is composed of lateral hypocotyl roots, strongly branching in the soil, and an embryonic root. This layer performs the main functions of supplying the plant with food and water for $2 \ldots 3$ weeks. 
The second layer of roots is formed from the coleoptile node due to the increase in the depth of planting seeds. These roots - epicotyls - develop most strongly at a seeding depth of $10 \ldots 14 \mathrm{~cm}$. The role of these roots in nutrition is insignificant. Third tier - the main or nodal roots are most important for the corn plant, they are formed from close nodes of the stem under the soil surface and at the beginning grow horizontally, then go down to a depth of more than $2 \mathrm{~m}$. The number of these roots reaches $20 \ldots 30$ pcs., they strongly branch. The bulk of the roots is located in the $0 \ldots 30 \mathrm{~cm}$ horizon. Supporting roots are formed on the second or third, and in late-maturing forms - on the sixth to seventh above-ground stem nodes, which, reaching the soil, form lateral roots and hairs. The main function is to prevent lodging and provide partial nutrition to plants. Corn roots have increased requirements for aeration and therefore (unlike other cereals) there are air cavities, and the deeper the roots are located, the larger they are.

The third object of field experiments was sowing soybeans (Glycine hispida Max.) - an annual herb. The root system is tap-root one, it consists of a short main root and a large number of long lateral roots, which go deep into the soil up to $2 \mathrm{~m}$.

Soybean root is tap-root one, short, coarse, with many long, well-developed lateral roots. The main root is thick in the upper part, but after $10-15 \mathrm{~cm}$ it quickly decreases in diameter and does not differ from the lateral roots, which, in turn, branch many times. The root system develops mainly in the arable layer at a depth of $30 \mathrm{~cm}$, individual roots can reach a depth of $45 \ldots 50 \mathrm{~cm}$.

For all three cultures, the mathematical analysis offered below, based on the method of J. Chow. The mathematical description of the patterns of the formation of root systems in corn and soybeans is expected to be published in subsequent articles.

\section{Methods}

The results of field studies carried out according to the methodology of N.Z. Stankov [8] which were devoted to the study of the morphobiological features of formation and development of the root system of sunflower grown using the Strip-Till technology were selected as material for mathematical modeling. The measurements of the parameters of the sunflower root system were carried out in the experimental field of the UNPO Povolzhye in the Engels district of the Saratov region. The agricultural landscape of the field is variable. The climate is characterized by cyclic aridization and corresponds to the arid conditions of the steppe zone of the South-East of Russia, the soil is dark chestnut.

The results of measurements showed that in sunflower the main root mass is located on average to a depth of $25 \div 26 \mathrm{~cm}$ and occupies a strip in a row with a width of about $13 \div$ $14 \mathrm{~cm}$ (Table 1).

Table 1 shows the values of the parameter $D$ - the degree of development of the root system (degree of sodding), which were determined considering the recommendations of fractal geometry [3] according to the method of N.Z. Stankov [4, 8]:

$$
D=\ln (B) \cdot \ln (L)
$$

where $\mathrm{B}$ and $\mathrm{L}$ are branching width and root length are parameters characterizing the intensity of filling the root space. Attention to the study of this factor is due to the fact that the higher the value of $\mathrm{D}$, the more intensively the filling of the soil space with the root system occurs and, accordingly, the efficiency of the growing season of the row crop increases. 
Table 1. Parameters of the washed sunflower root system during the growing season determined by the method [6].

\begin{tabular}{|l|c|c|c|c|c|c|c|c|c|c|c|c|}
\hline $\begin{array}{l}\text { Sa } \\
\mathbf{m p l} \\
\text { e o }\end{array}$ & $\mathbf{1}$ & $\mathbf{2}$ & $\mathbf{3}$ & $\mathbf{4}$ & $\mathbf{5}$ & $\mathbf{6}$ & $\mathbf{7}$ & $\mathbf{8}$ & $\mathbf{9}$ & $\mathbf{1 0}$ & $\mathbf{1 1}$ & $\mathbf{1 2}$ \\
\hline $\begin{array}{l}\text { Len } \\
\text { gth, } \\
\text { c, } \\
\text { cm }\end{array}$ & 26 & 18 & 23 & 27 & 25 & 20 & 16 & 24 & 26 & 25 & 29 & 23 \\
\hline $\begin{array}{l}\text { Wid } \\
\text { th, } \\
\begin{array}{l}B, \\
\text { cm }\end{array}\end{array}$ & 14 & 10 & 12 & 13 & 14 & 12 & 13 & 15 & 16 & 13 & 12 & 11 \\
\hline $\begin{array}{l}\text { Root } \\
\text { deve } \\
\text { lop } \\
\text { men } \\
\text { t } \\
\text { degr } \\
\text { ee, } \\
D\end{array}$ & 8.59 & 6.65 & 7.79 & 8.45 & 8.49 & 7.44 & 7.11 & 8.61 & 9.03 & 8.26 & 8.37 & 7.52 \\
\hline
\end{tabular}

In the process of implementing the Strip-Till technology, it was found that the degree of development of the sunflower root system, characterized by the value of parameter $D$, is significantly influenced by the agrophysical parameters of the cultivated soil layer, namely: $W$ - moisture reserve in the soil and $P$ - soil density.

In Table 2, the experimental data on soil density and the reserve of productive moisture in a meter layer during the growing season of sunflower when combining the main tillage system with elements of Strip-Till technology are compared with the degree of development of the sunflower root system for the samples from Table 1. The data were obtained on a study plot with an area of $100 \mathrm{~m}^{2}$ according to the method of B.A. Dospekhov [5]. The density of the soil during the measurement period was in the range of $1.08 \ldots 1.40 \mathrm{~g} / \mathrm{cm}^{3}$, which is consistent with the methodological recommendations of I.B. Revuta [7].

Table 2. The results of measurements of the agrophysical parameters of the cultivated soil layer and their comparison with the degree of development of the sunflower root system.

\begin{tabular}{|c|c|c|c|c|c|c|c|c|c|c|c|c|}
\hline $\begin{array}{c}\text { Sampl } \\
\text { e № }\end{array}$ & 1 & 2 & 3 & 4 & 5 & 6 & 7 & 8 & 9 & 10 & 11 & 12 \\
\hline $\begin{array}{l}\text { Moistur } \\
\mathrm{e} \\
\text { reserve, } \\
W, \mathrm{~mm}\end{array}$ & 13.0 & 11.8 & 12.7 & 12.0 & 14 & 12.4 & 12.3 & 14.4 & 13.0 & 13.2 & 13.6 & 14.0 \\
\hline $\begin{array}{l}\text { Soil } \\
\text { density } \\
P, \\
\mathrm{~g} / \mathrm{cm}^{3}\end{array}$ & 1.10 & 1.40 & 1.28 & 1.10 & 1.12 & 1.32 & 1.39 & 1.15 & 1.20 & 1.22 & 1.09 & 1.29 \\
\hline $\begin{array}{l}\text { Root } \\
\text { develop } \\
\text { ment } \\
\text { degree, } \\
D \\
\end{array}$ & 8.59 & 6.65 & 7.79 & 8.45 & 8.49 & 7.44 & 7.11 & 8.61 & 9.03 & 8.26 & 8.37 & 7.52 \\
\hline
\end{tabular}


To study the mutual influence of morphometric and agrophysical factors on the degree of root development, the method of probabilistic modeling was applied, based on replacing a real object with its statistical model [9].

At the preliminary stage of statistical processing of experimental data from Tables 1 and 2 , a correlation analysis of the factors that most significantly affect the effective indicator $D$, as well as an assessment of their significance, was carried out.

To do this, using the Correlation tool of the MS Excel spreadsheet processor analysis package, a matrix of paired correlation coefficients has been built, which determine the closeness of the statistical relationship between each of the factors $B, L, P, W$ with effective indicator $D$ and with each other. The assessment of the significance of the correlation coefficients was performed on the basis of the Student's $t$-criterion with the significance level $\alpha=95 \%$. It was found that there is a statistical relationship between all the variables under consideration, and the dependent variable $D$ has the closest relationship with the soil density $P$ and the moisture reserve in the soil $W$ (the cross-correlation coefficients for them are, respectively, $r_{D P}=-0.819$ and $\left.r_{D W}=0.44\right)$.

\section{Results}

Based on the results of the correlation analysis, a multiple regression model was built (1), in which the following designations were used: $D=D(W, P, L, B)$ - the degree of development of the root system, $W$ - moisture reserve in the soil, $P$ - soil density, $B-$ branching width, $L$ - root length. The model considers both the factors of the first $W, P, L$, $B$, and the second order $W * P, W * L, W * B, P * L, P * B, L * B$, determined by the products of the main factors.

$$
D=b_{0}+b_{1} W+b_{2} P+b_{3} L+b_{4} B+b_{5} W P+b_{6} W L+b_{7} W B+b_{8} P L+b_{9} P B+b_{10} L B,
$$

Here $b_{0}-b_{10}$ are multiple regression coefficients.

It is known that the more factors there are in the data model, the more accurate is the approximation of the effective indicator by the regression function. Therefore, as is customary in practice, model (1) considers all possible factors influencing $D$, with subsequent one-by-one checking for the significance of their influence on the degree of development of the sunflower root system. For this purpose, for each factor, the values of the standard coefficient of determination $R^{2}$ are performed.

$$
R^{2}=1-\frac{\sum_{i=1}^{n} e_{i}^{2}}{\sum_{i=1}^{n}\left(D_{i}-D_{c p}\right)^{2}},
$$

where $n$ is the number of points in the data set, $D_{i}$ is the current value of the parameter $D, D_{\text {avg }}$ is its average value, $e_{i}$ is the deviation of the actual value of the dependent variable from its value obtained by calculation and the corrected coefficient of determination $R_{c}{ }^{2}$,

$$
R_{\mathrm{c}}^{2}=1-\frac{(n-1) \cdot\left(1-R^{2}\right)}{m-n}
$$

where $m$ is the number of factors, $n$ is the number of data points in the dataset. The calculations are performed twice: with the initial set of factors and after removing one factor from the data model (1). If, after removing the selected factor from the data model, the adjusted coefficient of determination turns out to be greater than the originally 
calculated value, then this means that the factor insignificantly affects the dependent variable $D$. Therefore, according to the degree of decrease in the value of the adjusted coefficient of determination $R_{c}{ }^{2}$, one can judge the degree of influence of the removed factor on the effective indicator $D$.

It was found that the greatest influence on the degree of development of the root system of sunflower $D$ is exerted by soil density, i.e. factor $P$. The second most important factor is the moisture reserve in the soil $W$. Factors $L$ and $B$ have a slightly less significant effect, i.e. the length of the root and the width of its branching.

Additional study has shown that of the second-order factors, the greatest influence on $D$ is exerted by the products $P * B, P * L$, which characterize the mutual influence of soil density $P$ and morphometric parameters of the sunflower root system. The mutual influence of the parameters of the second order of smallness, determined by the products $W^{*} P, W^{*} L$, $W^{*} B$ and $L^{*} B$, on the degree of development of the root system $D$ turned out to be negligible.

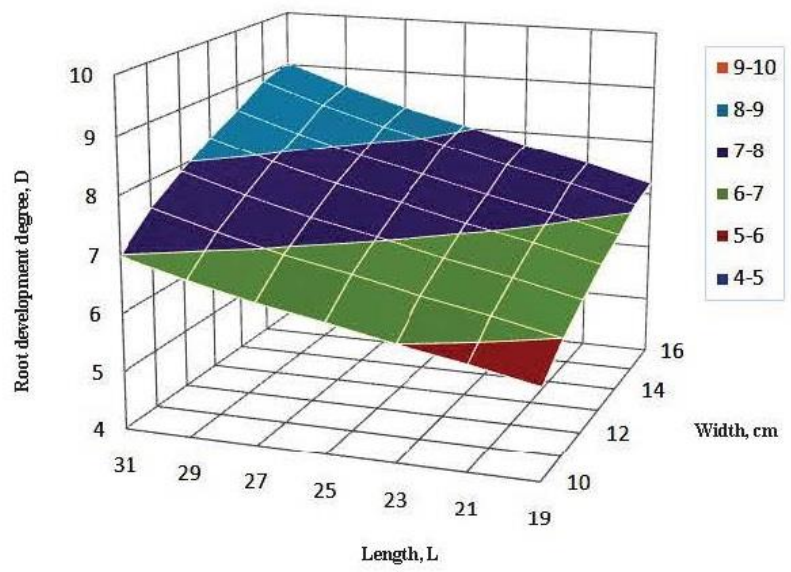

Fig. 1. Dependence of the degree of development of the sunflower root system on the morphometric parameters of the root system.

Regression and correlation analyzes of experimental data made it possible to establish that the most significant factors affecting the degree of development of the root system $D$, and, ultimately, the yield of sunflower, are the bulk density of the soil $P$, the level of productive moisture in the root-inhabited meter layer $W$, branching width $B$ and root length $L$.

The response surface of the regression model for $D=D(W, P, L, B)$ is a multidimensional hypersurface, the graphical representation of which on a plane is complicated by the complexity of its structure and is possible only in the form of separate three-dimensional sections, presented in Figures 1 and 2. 


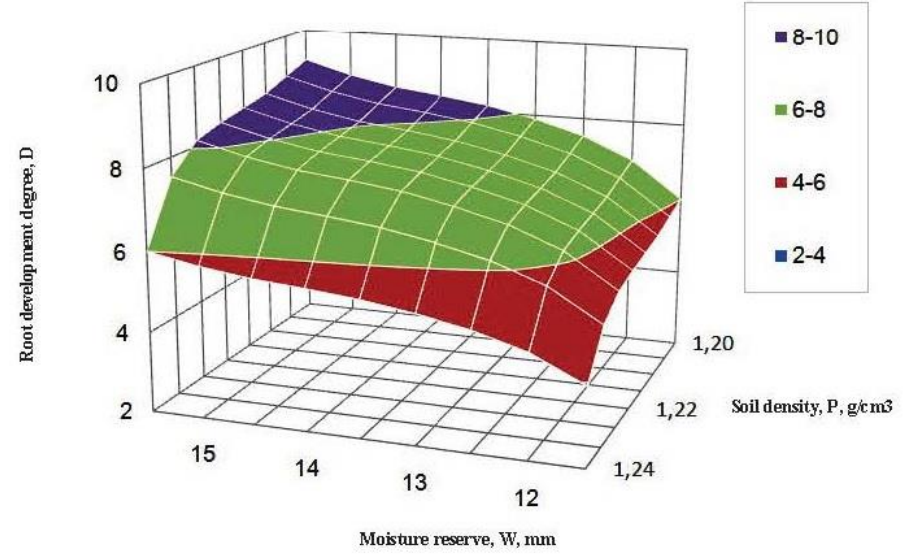

Fig. 2. Dependence of the degree of development of the sunflower root system on the agrotechnical parameters of the soil.

The plots in Figures 1 and 2 show that the response surface has a complex shape, the description of which requires the use of non-linear functions. This is also indicated by the two-dimensional sections shown in Figures $3 a$ and $3 b$.

Figures $3 \mathrm{a}$ and $3 \mathrm{~b}$ clearly show that for the values of the parameters $P \approx 1.225 \ldots$ $1.235 \mathrm{~g} / \mathrm{cm}^{3}$ and $W \approx 12.75 \ldots 13.25 \mathrm{~mm}$ there is a rapid drop in $D$ value, i.e. changes in the dynamics of the process of root formation, which must be taken into account when choosing and analyzing a data model, which can be built either on the basis of a strongly nonlinear or piecewise linear function [2]. The second option is preferable because practice shows that simple linear models have significant advantages over more complex nonlinear models. These advantages are due to the general "robustness" of linear models - their resistance to inaccurate specifications, to structural shifts and parameter drift.

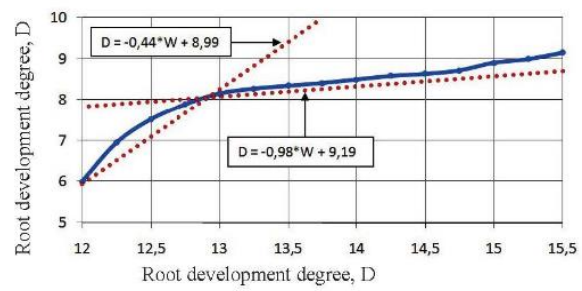

(a)

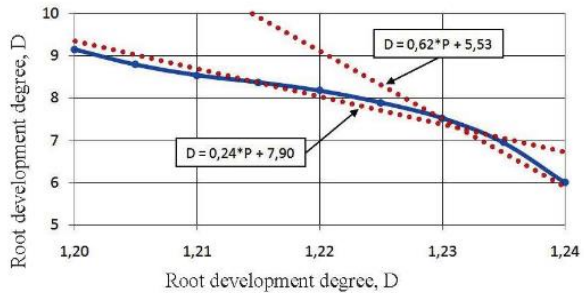

(b)

Fig. 3. Dependence of the degree of development of sunflower roots D on P - soil density (a) and W - moisture reserve (b) (solid lines) and trend lines for the values of parameter $\mathrm{D}$, with significantly different patterns of change (dotted lines).

In order to determine the optimal values of key parameters important for analysis and development of practical recommendations, a piecewise linear regression model was built and its parameters were estimated. 


\section{Discussion}

In the practical implementation of the piecewise linear regression model, the problem arose of determining the position of the points of change in the data structure, and, accordingly, the choice of quality data model.

Usually, to establish the fact of a change in the structure ("break") of the data, an analysis of the residuals and the behavior of the regression coefficients, as well as quality indicators of the model are carried. This procedure is not automatized; it is not reliable enough, requires processing of large arrays of auxiliary data and takes a long period of time [9].

The authors used a more sensitive and efficient method of determining the points of data structure change, based on the Chow criterion (J. Chow) [10] easily amenable to digital automation.

According to this criterion, the hypothesis that two parts of some random process are elements of one combined sample, shall be rejected if the Chow parameter $C h>F\left(k_{1}, k_{2}\right)$, where $F\left(k_{1}, k_{2}\right)$ is the value of the Fisher's criterion with the number of degrees of freedom $k_{1},\left(k_{1}\right.$ is the number of independent variables in the regression equation) and $k_{2}=p-k_{1^{-}} 1$, $p$ is the number of sample elements.

For a two-part sample, the Chow parameter is defined as follows:

$$
\begin{gathered}
C h=\frac{\left[S-\left(S_{1}+S_{2}\right)\right] /(k+1)}{\left(S_{1}+S_{2}\right) /\left[N_{1}+N_{2}-2(k+1)\right]} ; \\
S_{1}=S_{1 D W}-\frac{S_{1 D W}^{2}}{S_{1 W W}} ; \\
S_{2}=S_{2 D W}-\frac{S_{2 D W}^{2}}{S_{2 W W}} ; \\
S_{W W}=\sum_{i=1}^{N}\left(W_{i}-W_{c p}\right)^{2} ; \\
S_{D D}=\sum_{i=1}^{N}\left(D_{i}-D_{c p}\right)^{2} ; \\
S_{D W}=\sum_{i=1}^{N}\left(W_{i}-W_{c p}\right)\left(D_{i}-D_{c p}\right) ; \\
D_{c p}=\frac{1}{N} \sum_{i=1}^{N} W_{i=1}^{N} ;
\end{gathered}
$$


where $N_{l}, N_{2}$ are the number of points in the first and second parts of the sample, $D_{i}$ is the current value of parameter $D, D_{\text {avg }}$ is its average value, $W_{i}$ is the current value of the parameter $W, W_{\text {avg }}$ is the average value of this parameter, $S, S_{1}, S_{2}$ are the sum of the squares of the regression residuals obtained from the combined sample and its separate parts, $N=$ $N_{l}+N_{2}$ - the number of points in the combined sample, $p=N, k=k_{l}$.

The numerical values of the parameters corresponding to the break points of the data model are determined in the process of a recursive step-by-step algorithm. The algorithm is implemented as follows. Starting from the first $3 \ldots 5$ points of the data set, the first section of linear regression is built using the lookup table and built-in statistical functions of the MS Excel spreadsheet processor. Then 3 ... 5 more points are added, and a new regression line is constructed from them. The Chow test is applied to these two sites, considered as separate subsamples. If the criterion is not met, then, starting from the last point of the second section, the whole procedure is repeated for the next $3 \ldots 5$ points. If Chow's criterion is satisfied, then the coordinate of the last point of the first of two successively considered subsamples is taken as the coordinate of the break point of the piecewise-linear data model. The number of "trial" points is selected depending on the total sample size and the degree of "ruggedness" of the predicted function.

\section{Conclusion}

It was found that the degree of development of the sunflower root system is in direct proportion to the supply of productive moisture in the root layer of the soil and in inverse relationship to its density.

The obtained mathematical predictive models of the development of the sunflower root system allow with a reliability of $87 \ldots 95 \%$ to determine the degree of development of its root system, depending on moisture reserves, soil density without long and laborious field morphometric experiments.

In practice, for the most complete implementation of the resource-saving potential of Strip-Till strip tillage technology on sunflower crops, it is advisable to provide a loosening depth of $28 \ldots 30 \mathrm{~cm}$ and a strip width of $20 \mathrm{~cm}$ with a working width of $70 \mathrm{~cm}$, adding small additional gaps of $4 . . .6 \mathrm{~cm}$.

To increase the accuracy and reliability of choosing the optimal combination of morphometric and agrophysical factors of the root system of a highly profitable crop sunflower, it is advisable to limit the range of permissible parameter values to the values $P$ $\geq 13 \mathrm{~mm}$ and $W \leq 1.23 \mathrm{~g} / \mathrm{cm}^{3}$. Outside the indicated limits, the value of the indicator of the degree of development of the root system $D$ rapidly decreases, indicating a sharp decrease in the efficiency of root formation and, ultimately, the yield of the row crop as a whole.

In general, the studies carried out made it possible to obtain results confirming the advantage of introducing a combined method of soil cultivation using the Strip-Till system in the dry steppe zone of the South-East of Russia [6].

\section{References}

1. National program «Digital Economy of the Russian Federation» (2019)

2. H. Kantz, N. Scheiber, Nonlinear Time Series Analysis (Cambridge University Press, 2004)

3. V. K. Balkhanov. Fundamentals of fractal geometry and fractal calculus (Publishing house of the Buryat State University, 2013) 
4. V.M. Boykov, S.V. Startsev, I.L. Vorotnikov, V.B. Narushev, Agrarian Scientific Journal, 9 (2020)

5. B.A. Dospekhov, Field experiment technique (with the basics of statistical processing of research results) (AGROPromizdat, 1985)

6. Yu.A. Kuzychenko, R.S. Stukalov, R.G. Gadzhiumarov, Bulletin of the Lower Volga Agricultural University Complex: Science and Higher Professional Education, 57, 1 (2020)

7. I.B. Roar, Soil Physics (Kolos, 1972)

8. N.Z.Stankov, Root system of field crops (Kolos, 1964)

9. N.Draper, Applied Regression Analysis (2019)

10. Ch. Dougherty, Introduction to Econometrics (Oxford University Press, 2007) 